\title{
ESTIMATION OF CALCIUM CARBONATE IN SOILS.
}

\author{
By F. S. MARR, M.A., B.Sc. \\ Carregie Research Scholar. \\ Rothansted Experiment Station.
}

T'His work was undertaken at the suggestion of Mr A. D. Hall, whose attention was drawn to the subject by some abnormal results obtained in the estimation of calcium carbonate in certain soils from different parts of the world characterised by their high bumus content and their acid reaction to litmus paper. Boiled with diluted sulphuric acid ( $1: 1 \mathrm{H}_{2} \mathrm{SO}_{4}$ ), most of these soils yielded an amount of carbon dioxide (estimated by Brown and Escombe's double titration method) equivalent to a percentage of $1-3$ of calcium carbonate in the air dried soil: while others yielded still bigher amounts. It is quite possible that a soil may be acid in reaction and yet contain carbonate ${ }^{1}$, but such percentages are quite incompatible with the strong acidity present in these cases. It seemed possible that the carbon dioxide evolved from such soils when boiled with acid resulted from the decomposition of unstable organic matter: and this is the conclusion arrived at by the writer.

The apparatus used in the investigation was that described by $A \operatorname{mos}^{2}$.

Two soils which showed specially high percentages of carbonate (as calculated from the carbon dioxide evolved) were selected as test soils. These will be referred to under their Laboratory numbers, Ohio I, and Transvaal IIr: in addition use was made of many other soils both acid and normal. They were used in an air dried condition, and powdered till they would pass through a sieve with square holes, passing particles less than $0.4 \mathrm{~mm}$. in diameter. The test for decomposition of organic matter with production of carbon dioxide was carried out as follows. 10 grams of soil were placed in a basin with 50 c.c. of boiled water, and 15 c.c. of strong hydrochloric acid added. The basin was placed in a

1 Hall, Miller, and Gimingham, Proc. Roy. Soc. B. 1908, 80, 196.

2 Journal of Agricultural Science, 1905, 1. 322. 
desiccator over strong caustic soda and a good vacuum obtained by means of a Fleuss pump. The whole was allowed to stand for several hours in order to ensure the decomposition of the carbonate, after which time the contents of the basin were washed into the distilling flask of the carbon dioxide apparatus with 50 c.c. of water, and boiled for twenty minutes. The absorbing Reiset tower was then detached and the carbon dioxide estimated. The distillation was then continued for a second period of twenty minutes, and also for a third, with the following result. The figures are given in milligrams of carbon dioxide per 100 grams of soil.

\begin{tabular}{|c|c|c|c|}
\hline Soil & 1st 20 mins. & 2nd 20 mins. & 3rd 20 mins. \\
\hline Transvaal III ...... & 422 & 224 & 211 \\
Ohio I ............. & 316 & 171 & 136 \\
\hline
\end{tabular}

The results indicate the continued decomposition of something in the soil which yields carbon dioxide but which can hardly be calcium or any other earthy carbonate. Even if any carbon dioxide remained dissolved in the acid solution standing in the vacuum, it would have been removed during the first boiling, so that the carbon dioxide obtained in the second and third boilings must have been freshly formed by the slow decomposition of the organic matter in the soil.

An attempt was then made to minimise the decomposition of organic matter by substituting ammonium chloride for the acid-

$$
\mathrm{CaCO}_{3}+2 \mathrm{NH}_{4} \cdot \mathrm{Cl}=\mathrm{CaCl}_{2}+\left(\mathrm{NH}_{4}\right)_{2} \mathrm{CO}_{3} \text {. }
$$

Hartleb and Stutzer ${ }^{1}$ used ammonium chloride instead of hydrochloric acid, and estimated carbonate as ammonia. This method is open to criticism, and was found to be quite unreliable for acid soils, the free acid of which combines with the ammonia produced and thus renders the results too low. In the case of a New Zealand acid soil less ammonia came over in the distillation of ammonium chloride with soil than in the blank distillation of the ammonium chloride solution itself.

There can, however, be no objection to a distillation with ammonium chloride if the carbon dioxide arising from the dissociation of the ammonium carbonate is estimated, and the carbonate calculated from this figure: this was done by the writer. $10-20$ grams of the fine soil were put into the distilling flask along with 75 c.c. of boiled water.

1 Zeit. angew. Chem. 1899, xIr. 448. 
50 c.c. of a $20 \%$ solution of ammonium chloride were introduced by means of a 3-way funnel, and the distillation was continued for thirty minutes after the contents of the distilling flask reached the boil. The same apparatus as before was used, with the addition of an acid trap containing dilute sulphuric acid and fitted with a condenser. This trap was provided to prevent ammonia from reaching the absorbing Reiset tower, as it was found that ammonia interfered with the phenol-phthalein titration rendering it slower and less sharp. The results obtained by this method (expressed as before in milligrams of carbon dioxide per 100 grams of air-dried soil) were always lower than those obtained with hydrochloric acid.

\begin{tabular}{|c|c|c|}
\hline Soil & 1st 30 mins. & 2nd 30 mins. \\
\hline Transvaal III ...... & 83 & 65 \\
Ohio I ............. & 140 & 79 \\
\hline
\end{tabular}

A series of soils yielder on the average 52 milligrams more carbon dioxide per 100 grams of soil by distillation with hydrochloric acid than with ammonium chloride. The subsoils agreed very closely, a difference of only 12 milligrams carbon dioxide per 100 grams soil being obtained on the average. This points to the organic matter, which is comparatively speaking absent in the subsoil, as the source of the extra carbon dioxide evolved from the surface soil.

The next step was to ascertain whether by boiling such soils with water alone any evolution of carbon dioxide took place. This was invariably found to be the case. The results, calculated as before, are given in the following table. 125 c.c. of water was used and the boiling continued for 30 minutes.

\begin{tabular}{|c|c|c|}
\hline Soil & 1st 30 mins. & 2nd 30 mins. \\
\hline Transvaal III ...................... & 66 & - \\
Ohio I ......................... & 94 & 39 \\
New Zealand Virgin Pasture... & 47 & - \\
Plot 11 Rothamsted Pasture... & 22 & - \\
\hline
\end{tabular}

As it was highly improbable that these soils, all of which showed a strong acid reaction to litmus, contained any appreciable amount of carbonate, and as they gave off carbon dioxide on boiling with water 
alone, it seemed impossible in such cases to obtain an accurate estimation of the carbonate by any method in which the soil was subjected to the decomposing effect of water boiling under atmospheric pressure.

Extraction with ammonium sulphate in the cold was next tried. The soil was shaken for twelve or more hours with a strong solution of ammonium sulphate, and allowed to stand till the supernatant liquid was quite clear. An aliquot portion was then pipetted off by means of a filter pump (to avoid disturbing the fine sediment at the bottom of the extraction flask), and the carbon dioxide estimated by boiling in Amos' apparatus, a little sulphuric acid being added to prevent ammonia from reaching the absorbing Reiset tower. While negative results were got for carbonate in the acid soils tested, the normal soils always showed carbonate though in quantities below those estimated by direct treatment with acid. The carbonate could al ways be determined with a considerable degree of accuracy by the following procedure. First of all, the carbon dioxide was estimated by Amos' method. The same amount of soil was then boiled with dilute hydrochloric acid for a similar period of time under like conditions after standing in a vacuum as described in the first experiment to verify the decomposition of organic matter. The figure for the carbon dioxide evolved from carbonate was found by subtracting the amount of carbon dioxide evolved in the latter estimation from the total found in the former. The method is not free from objection owing to the difficulty of maintaining the experimental conditions exactly similar, but can be relied on as giving very satisfactory results. In normal alkaline soils containing $1-2 \%$ carbonate of lime, the amount of carbon dioxide evolved on boiling with pure water was on the average 44 milligrams of carbon dioxide per 100 grams soil which corresponds to $0.1 \%$ carbonate of lime. As the ammonium chloride method gave results that were much too low in comparison with those obtained in the manner described, it was abandoned as unreliable.

Extraction with water supersaturated with carbon dioxide also failed to give satisfactory results. The excess of carbon dioxide was boiled off and acid added to decompose the precipitated carbonate, but the results obtained were very erratic.

Finally, a distillation with very dilute acid at reduced pressures was tried and adopted as giving results which were very satisfactory compared with those obtained by distilling the soil under atmospheric pressure. Transvaal III, which, as the ammonium sulphate extraction showed, contained no carbonate, yielded when boiled with water alone 
under reduced pressure 7 milligrams of carbon dioxide per $100 \mathrm{gm}$., an amount which scarcely exceeds the unavoidable experimental error, and certainly shows that water alone did not decompose any appreciable amount of organic matter under these conditions. 20 grams of the Transvaal soil were now taken and boiled for 20 minutes at $50^{\circ} \mathrm{C}$. with 2 c.c. strong hydrochloric acid and 100 c.c. water. 19 milligrams of carbon dioxide per 100 grams soil were obtained and on continuing the process 11 milligrams. The contents of the distilling flask were now boiled for 20 minutes at atmospheric pressure and 158 milligrams were now evolved. It will be observed that the strength of the acid is an important factor in determining the amount of decomposition, as this soil yielded 422 milligrams carbon dioxide when boiled with the stronger acid used in the test for the decomposition of organic matter. The Sprengel water pump was used to reduce the pressure, and considerable care must be exercised during the experiment, especially when allowing air to pass through the apparatus on the completion of the decomposition of the carbonate.

The results obtained by this method with eight acid soils tested never, with the exception of Ohio I and Transvaal III, rose above 9 milligrams carbon dioxide per 100 grams soil, while on boiling at atmospheric pressure ten times as much was found, and that after all carbonate must have been decomposed. 9 milligrams of carbon dioxide corresponds to $0.02 \%$ calcium carbonate, and whether a soil contains this amount or no carbonate at all is a matter of no great importance.

The following table gives a comparison of the results obtained for the carbon dioxide in Transvaal III and Ohio I by the various methods tried.

\begin{tabular}{|c|c|c|c|c|c|c|}
\hline Soil & $\begin{array}{c}\text { With } \\
1: 1 \mathrm{H}_{8} \mathrm{SO}_{4}\end{array}$ & $\begin{array}{c}\text { With dilute } \\
\text { HCl at } \\
\text { atmospheric } \\
\text { pressure }\end{array}$ & $\begin{array}{c}\text { With } \\
\mathrm{NH}_{4} \text { Cl } \\
\text { (distilla- } \\
\text { tion) }\end{array}$ & $\begin{array}{c}\text { With } \\
\text { boiling } \\
\text { water }\end{array}$ & $\begin{array}{c}\text { With } \\
\mathrm{NH}_{4} \text {.Cl } \\
\text { (extraction) }\end{array}$ & $\begin{array}{c}\text { With dilute } \\
\text { HCl under } \\
\text { reduced } \\
\text { pressure }\end{array}$ \\
\hline Transvanl III. & 1540 & 422 & 83 & 66 & 0 & 19 \\
Ohio I ......... & 2772 & 316 & 140 & 94 & 0 & 12 \\
\hline
\end{tabular}

An attempt was made to isolate from Transvaal III and Ohio I a portion of the organic matter which, boiled at atmospheric pressure with dilute hydrochloric acid, should give off a much larger percentage of carbon dioxide than the soil itself. For this purpose part of the 
humus was extracted with $4 \%$ ammonia after preliminary treatment with $1 \%$ hydrochloric acid, which was removed before extracting with ammonia. Curiously enough, the percentage of carbon dioxide evolved from the humus, which was dried in a desiccator over sulphuric acid, did not increase, although the same experimental conditions were maintained as before.

Amos' observations on the occlusion of carbon dioxide in soil were repeated and confirmed. It was found that occlusion of carbon dioxide in air-dried soil does not take place to any appreciable extent.

I have to thank $\operatorname{Dr} N$. H. J. Miller of this laboratory for his continued advice and assistance during the progress of this work.

\section{Summary and Conclusions.}

Boiling acid at atmospheric pressure decomposes organic matter in soil with evolution of carbon dioxide, and thus renders the results obtained for carbonate too high. Where there is a fairly large percentage of carbonate, the error introduced in this way is of no great importance, but in soils containing less than $1 \%$ of calcium carbonate and especially in acid soils, the error introduced by thus boiling with acid may be very considerable.

The weaker the acid used the better so long as there is fair excess. The writer recommends for acid soils and those containing low percentages of carbonate (as can be seen by making a rough preliminary test), 2 c.c. of strong hydrochloric acid and about 100 c.c. of water: 20 grams of soil should be used when the amount of carbonate is small. The acid may be conveniently added by making up a solution containing 100 c.c. of strong hydrochloric acid per litre, and introducing 20 c.c. of this solution along with 80 c.c. of water. For most soils, 5 c.c. of strong hydrocbloric acid to 100 c.c. of water will be found convenient.

If possible distillation under reduced pressure should be used, as under this condition practically no decomposition of organic matter takes place, while carbonate is readily decomposed: the distillation should be continued for twenty minutes at a temperature of about $50^{\circ} \mathrm{C}$.

Since the above paper was ready for publication we have learnt of the death of the author at Breslau on May 13th. After working for a year in the Rothamsted Laboratory Mr Marr proceeded to Breslau to work under Dr Th. Pfeiffer, and there the course of a promising worker, who endeared himself to all with whom he came in contact, was untimely cut short.

A. D. H. 